were doing many of them, we used the Atlas Computer (Rees, 1964).

Correlation of electrocardiographic changes with the other variables showed that the abnormal E.C.G.s were significantly associated with body-weights in that specific changes occurred seldom in underweight patients (tau $=0.44 ; \mathrm{P}=0.02$ ) and never in our obese patients (tau $=-0.46 ; \mathrm{P}=0.02$ ), which contrasts with previous observations (Evans, 1959) that patients with these changes tend to be overweight. Our results also suggested that the specific E.C.G. abnormalities correlated with height (less common in the tall, tau $=-0.25, \mathrm{P}=0.1$ ), with the presence of abnormal cardiovascular signs, and with the absence of peripheral neuropathy, but the last two correlations are significant only at the $\mathbf{P}=0.2$ (approximately) level.

In considering the intercorrelations between abnormalities other than E.C.G. it was found that the admitted daily intake of alcohol was positively correlated with the presence of peripheral neuropathy (tau $=-0.44 ; \mathrm{P}=0.028$ ), as might be expected, but that it was negatively correlated with the presence of delirium tremens (tau $=-0.40 ; \mathrm{P}=0.036$ ) and with liver tenderness or enlargement (tau $=-0.43 ; \mathrm{P}=0.036)$.

\section{Summary}

In a series of 37 psychiatric in-patients with alcoholism 20 had abnormal E.C.G.s. The usual changes found were those described by Evans as specific for alcoholic cardiomyopathy (dimple and cloven $\mathrm{T}$ waves); many reverted to normal during hospital admission. An abnormal E.C.G. was the physical abnormality most often found in these patients.

The abnormal E.C.G.s were significantly associated with body-weight, occurring seldom in underweight patients (tau $=-0.44 ; \mathrm{P}=0.02$ ), and never in our obese patients (tau $=$ $-0.46 ; \mathbf{P}=0.02)$. They showed a tendency to occur in the presence of abnormal cardiovascular signs.
The liver was enlarged or tender in 15 of the 37 patients (but in only one were the flocculation tests unequivocally abnormal).

In considering the physical health of the patients in this series, relevant symptoms, physical signs, or abnormalities of special investigations were found in 32 of the 37 patients.

We are grateful to Mr. D. J. Rees for preparing the computer programme, to Dr. K. Hope for advising on the statistical method, and to Dr. E. E. Robertson for permission to report on the patients under her care. The Honeywell Cardioview portable electrocardiograph was kindly lent by Vitamins Limited, and the work was supported by a grant from the Royal Edinburgh Hospital.

Note.-For reasons of brevity it has not been possible to give the complete data and statistical treatment, but details will gladly be furnished on request.

\section{REFERENCES}

Averill, K. H., and Lamb, L. E. (1960). Amer. F. Cardiol., 6, 76. Blackburn, H., Keys, A., Simonson, E., Rautaharju, P., and Punsar, S. (1960). Circulation, 21, 1160.

Brigden, W. (1957). Lancet, 2, 1179, 1243.

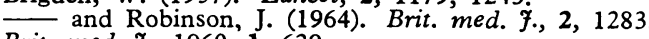

Brit. med. f., 1960, 1, 629.

Burch, G. E., Walsh, J. J., and Black, W. C. (1963). F. Amer. med. Ass., 183,81 .

Evans, W. (1959). Brit. Heart F., 21, 445.

- (1964). Progr. cardiovas. Dis., $7,151$.

Harrison, M. T., and Gibb, B. H.' (1964). Lancet, 2, 429.

Hickie, J. B., and Hall, G. V. (1960). Aust. Ann. Med., 9, 258.

Kelly, H. G., Fay, J. E., and Laverty, S. G. (1963). Canad. med. Ass. F. 89, 546.

Kendall, M. G. (1955). Rank Correlation Methods, 2nd ed. Griffin,
London. London.

Lancet, 1960, 1, 536.

Rees, D. J. (1964). Guide to a Survey Program for Atlas Computer Unit Report No. 2.

Simonson, E. (1961). Differentiation between Normal and Abnormal in Electrocardiography. Mosby, St. Louis.

Wendkos, M. H. (1963). Clin. Res., 2, 255.

Wendt, V. E., Stock, T. B., Hayden, R. O., Bruce, T. A., Gudbjarnason, S., and Bing, R. J. (1962). Med. Clin. No. Amer., 46, 1445. Zondek, H. (1964). Lancet, $2,1018$.

\title{
Incidence and Significance of Melanogenuria
}

\author{
J. C. CRAWHALL,* M.B., B.S., PH.D. ; BARBARA J. HAYWARD, $\dagger$ B.SC. ; C. A. LEWIS, $\dagger$ PH.D., A.R.I.C.
}

Brit. med. F., 1966, 1, 1455-1457

Some patients with malignant melanoma excrete urine containing abnormal metabolic products which darken on exposure to air and react under certain conditions with sodium nitroprusside to give a characteristic blue colour (Thormählen, 1887). This phenomenon is not found in the early stages of the disease, and Eppinger (1910) has suggested that it appears after the development of hepatic metastases.

The abnormal metabolites (melanogens) fall into two chemical classes-the phenol melanogens (3:4-dihydroxyphenylalanine and its metabolite, homovanillic acid), which are Thormählennegative (Duchon and Gregora, 1962 ; Scott, 1962), and the indole melanogens, which are Thormählen-positive and react characteristically with Ehrlich's p-dimethylaminobenzaldehyde reagent. Leonhardi (1954) and Duchon and Pechan (1963) effected the chromatographic separation of at least three Thormählen-positive substances, thought to be conjugation products of 5:6-dihydroxyindole. Pechan (1959) has evaluated

\footnotetext{
* Medical Professorial Unit, St. Bartholomew's Hospital, London. Temporary address, Clinical Centre, National Institutes of Health, Bethesda, Maryland, U.S.A.

† Department of Biochemistry, St. Bartholomew's Hospital Medical Colle ze, London.
}

the optimum conditions for the spectrophotometric determination of melanogens by the Thormählen reaction.

The biochemical and clinical significance of the melanogens has been review recently by Duchon and Pechan (1963).

In this investigation we have used paper chromatography and spectrophotometry as double criteria in a study of the incidence and extent of melanogen excretion in relation to the clinical state of the patient. We have studied the effect of cytotoxic drug therapy on melanogen excretion, and have made a comparison of plasma and urinary melanogen excretion and urinary melanogen concentration.

\section{Methods}

Analyses of urinary indole melanogens by paper chromatography and by a quantitative Thormählen technique were performed on early-morning specimens from every patient entering this hospital as an in-patient during 14 months in whom at any time a confirmed diagnosis of malignant melanoma had been made. If a positive result was obtained further analyses were made on 24-hour collections. Analyses were also per- 
formed on plasma and urine samples from one patient in another hospital. To provide a control series early-morning specimens were collected from 17 unselected patients in male and female medical wards, some of whom had malignant disease.

\section{Quantitative Thormählen Procedure}

Sodium nitroprusside ( $1 \%$ solution freshly prepared; $0.5 \mathrm{ml}$.) was added to urine $(0.5 \mathrm{ml}$.). To this was added sodium hydroxide $(10 \%$ solution ; $2 \mathrm{ml}$.) followed by acetic acid ( $30 \%$ solution ; $2 \mathrm{ml}$.). One minute after the last addition the absorption spectrum was determined by means of a Unicam recording spectrophotometer (SP700) over the range 400-700 $\mathrm{m} \mu$. The colour is not stable, and it decreased by $3 \%$ in five minutes.

A standard solution was made by dissolving indole $(10 \mathrm{mg}$.) in ethanol $(2 \mathrm{ml}$.) and diluting to $250 \mathrm{ml}$. with distilled water. This solution was stable for one year in a refrigerator.

The blue colour from the indole standard shows a broad maximum at $625 \mathrm{~m} \mu$, whereas control urines processed similarly show a decrease in optical density through the range 400$700 \mathrm{~m} \mu$. Melanogens were therefore considered to be present when the optical density at $625 \mathrm{~m} \mu$ exceeded that at $525 \mathrm{~m} \mu$.

\section{Paper Chromatography}

Volumes of urine containing $100 \mu \mathrm{g}$. of creatinine were subjected to two-dimensional chromatography on Whatman No. 1 paper in isopropanol/water/0.880 $\mathrm{NH}_{3}(200: 20: 10)$ followed by $n$-butanol/acetic-acid/water $(120: 30: 50)$, as described for indoles (Jepson, 1960). Duplicate chromatograms were treated with (1) Ehrlich's p-dimethylaminobenzaldehyde reagent (in acetone): melanogens gave a characteristic colour sequence-instant purple rapidly fading and reappearing as a light brown which slowly darkens; and (2) Thormählen reagent:powdered sodium nitroprusside was shaken for one minute with ethanol. The pale yellow solution was decanted and the chromatogram dipped without delay and dried. The paper was then dipped through ethanolic sodium hydroxide ( $40 \%$ aqueous solution, 1 vol.; ethanol, 9 vols.), dried, and finally dipped through $10 \%$ acetic acid in acetone. Melanogens gave a purple colour at the alkali stage, becoming blue after acidification.

The positions of three spots which gave positive melanogen reactions in both Ehrlich and Thormählen tests are shown in Fig. 1, with other common Ehrlich reactors. Spot 1 occurred most frequently, spot 3 less frequently. Control urines occasionally gave weak blue spots in the Thormählen test, one at the position of indoxyl sulphate (presumably indigo), and one in the vicinity of melanogen spot 1 , but neither of these gave the characteristic melanogen colour sequence with Ehrlich reagent.

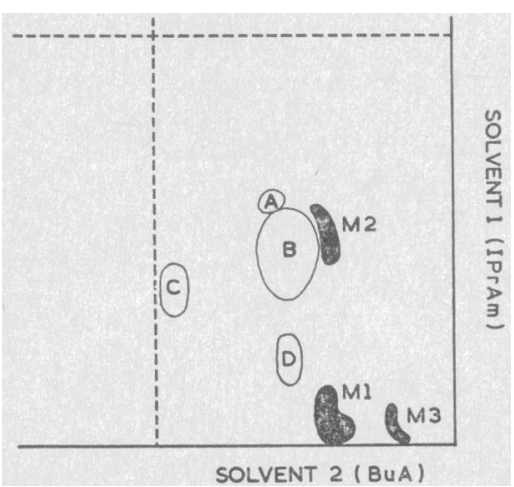

FIG. 1.-Diagram of chromatogram after location with Ehrlich's reagent. M1, M2, M3: Melanogens. A : Indoxyl sulphate.
B : Urea. C: Indoxylacetic acid. D : Tryptophan.

\section{Determination of Plasma Melanogens}

Heparinized plasma was obtained from a patient (in another hospital) with gross melanogenuria (1.4 g. indole equivalent/ 24 hours). Plasma proteins were found to interfere with the quantitative Thormählen reaction, and were removed by gel filtration.

Heparinized plasma ( $1 \mathrm{ml}$.) was added to a column of Sephadex G-25 (medium grade $5 \times 0.9 \mathrm{~cm}$.) suspended in water. Elution with water (0.5-ml. fractions) effected a clear separation between the proteins (fractions 6-10) and the melanogens (fractions 13-16), which were determined by the quantitative method described above. No Thormählen-positive fractions were obtained when plasma from a control patient was treated in this manner. Thormählen-positive substances were found in the same tubes when melanogen-containing urine was added to normal plasma before gel filtration: the recovery of melanogen was $80 \%$. Indole was adsorbed by the Sephadex and eluted slowly, and was therefore not suitable as a standard.

\section{Results}

Thirty-two patients were included in the investigation. The relation between their clinical state and the incidence of melanogenuria is shown in Table $\mathrm{I}$.

TABLE I-Relation Between Clinical State and Incidence of Melanogenuria

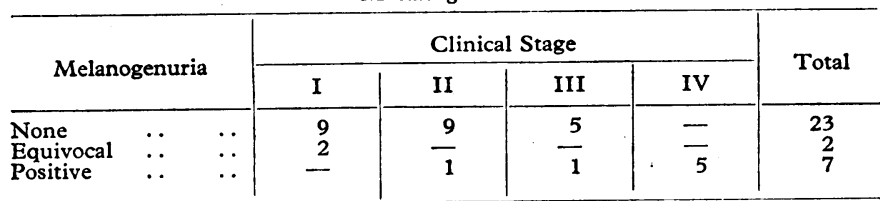

Clinical stages: I, primary tumour with no evidence of metastases; II, regional Clinical stages: I, primary tumour with no evidence of metastases; II, regional metastases with hepatomegaly.

Patients without Melanogenuria.-In all but three of these 23 patients the diagnosis had been made one year or more before investigation during the period under review. All remained alive during that time, though four of the patients in stage III were deteriorating despite treatment.

Patients with Equivocal Melanogenuria.-Two patients were found in whom the spectrophotometric and paper chromatographic tests for melanogenuria did not agree. Both were in stage I and remained well, and it is unlikely that these equivocal results are significant.

Patients with Melanogenuria.-Seven patients were found to have melanogenuria by both methods of testing. Details of these patients are set out in Table II. The two patients with the lowest melanogen excretions had no clinical evidence of hepatomegaly, but no post-mortem evidence was obtained in either case. Melanogenuria was absent when one patient (Case 4) was first seen at clinical stage III ; melanogenuria and hepatomegaly developed during the period of investigation.

Effect of Cytotoxic Drugs on Melanogen Excretion.-The patient (Case 6) had a primary rectal melanoma with inguinal gland involvement and a liver enlarged $1 \frac{1}{2}$ in. $(3.8 \mathrm{~cm}$.) beneath

\begin{tabular}{|c|c|c|c|c|c|}
\hline Case & Stage & History & Primary Site & Melanogens & Survival \\
\hline 1 & II & 5 years & Conjunctiva & $1 \mathrm{mg} . / 24 \mathrm{hr}$. & $\begin{array}{l}\text { Died after local } \\
\text { recurrence } \\
82\end{array}$ \\
\hline 2 & III & 3 & $\begin{array}{l}\text { Digital. } \\
\text { Subungual }\end{array}$ & $3.5 \mathrm{mg} / 24 \mathrm{hr}$. & $\begin{array}{l}\text { Died four months } \\
\text { later }\end{array}$ \\
\hline 3 & IV & 2 & $\begin{array}{l}\text { Abdominal } \\
\text { wall }\end{array}$ & $12.2 \mathrm{mg} . / 24 \mathrm{hr}$. & Probably not alive \\
\hline 4 & IV & $8 \mathrm{mths}$ & Unknown & $460 \mathrm{mg} . / 24 \mathrm{hr}$. & $\begin{array}{l}\text { Rapid death from } \\
\text { metastases }\end{array}$ \\
\hline 5 & IV & 11 years & Eye & $48 \mathrm{mg} \cdot / 24 \mathrm{hr}$. & $\begin{array}{l}\text { Died of a coronary } \\
\text { prior to treatment }\end{array}$ \\
\hline 6 & IV & $1 \frac{1}{2} \quad$ & Rectum & $30 \mathrm{mg} . / 1 \mathrm{~g}$. creat. & $\begin{array}{l}\text { Died at home after } \\
\text { four months }\end{array}$ \\
\hline 7 & IV & 7 , & Groin & $130 \mathrm{mg} / 1 \mathrm{~g}$. creat. & Died in ward \\
\hline
\end{tabular}


the costal margin. Cytotoxic drug therapy (mustine and cyclophosphamide) caused a decrease in size of the rectal primary and of the liver. The improvement was maintained for seven months, but subsequently the patient's condition deteriorated despite further mustine therapy, and he died four months later. Melanogen excretions were determined at intervals during treatment-the rapid initial fall and later changes in melanogen output are shown in Fig. 2.

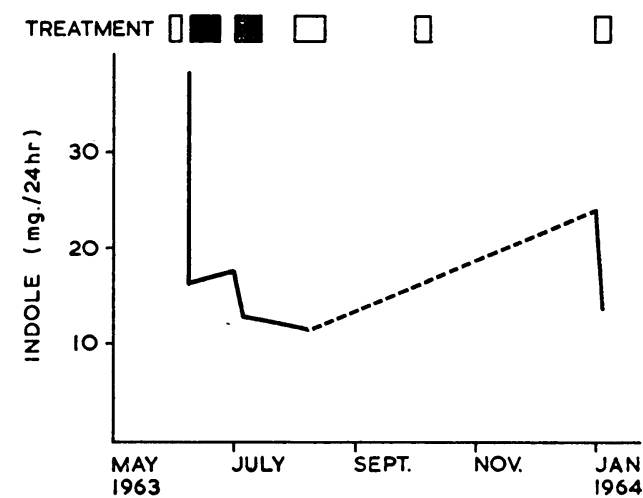

FIG. 2.-Changes in melanogen excretion during treatment with cytotoxic drugs. Mustine $\square$ and cyclophosphamide were given as indicated.

Plasma Melanogen Level.-A patient (in another hospital) with gross hepatomegaly, who had had an eye excised five years previously, was found to have a plasma melanogen concentration of $10 \mu \mathrm{g}$. indole equivalent $/ \mathrm{ml}$. and a urinary excretion of $1.4 \mathrm{~g}$. indole equivalent $/ 24$ hours. It was not possible to carry out any formal tests of renal function on this patient. It was observed that the plasma did not darken on standing nor on treatment with oxidizing agents (hydrogen peroxide or potassium ferricyanide).

\section{Discussion}

The two-dimensional chromatographic behaviour of compounds giving coincident Thormählen and Ehrlich reactions for melanogens has been presented. We have thereby confirmed Leonhardi's (1954) observation that three indole melanogens are found, though the full pattern may not be seen at the first appearance of melanogenuria.

The use of a recording spectrophotometer in the quantitative Thormählen test has overcome the difficulty of the high nonspecific absorption which may be present in some specimens, and has permitted a more precise identification of the specific absorption peak at $625 \mathrm{~m} \mu$. The limit of detection by the method is approximately $1 \mathrm{mg} . / 24 \mathrm{hr}$., but values below $5 \mathrm{mg}$./ $24 \mathrm{hr}$. should be viewed with caution unless corroborated by paper chromatography.

False-positive Thormählen reactions have been reported in a number of cases-for example, Beeler and Henry (1961) and Blackberg and Wanger (1933). We believe that the application of the combined criteria of spectrophotometry and paper chromatography should reduce the incidence of false-positive results, and at the same time facilitate the detection of early melanogenuria. Duchon and Pechan (1963) regard melanogen levels of up to $5 \mu \mathrm{g} . / \mathrm{ml}$. as normal; in 23 patients in our melanoma series and in 17 unselected in-patients (some of whom had malignant disease) we found that melanogens were below the limit of sensitivity, which is approximately $1 \mu \mathrm{g} . / \mathrm{ml}$. for both paper chromatographic and recording spectrophotometric methods.

Unequivocal melanogenuria was found in approximately $20 \%$ of the malignant melanoma patients in the present series, an incidence which is in agreement with earlier reports (Beeler and Henry, 1961; Duchoñ and Pechan, 1963). It can be seen from Table II that melanogenuria is not confined to any one type of primary site. Five of the seven patients with melanogenuria had clinical signs of hepatic metastases; the other two show that melanogenuria can occur without hepatomegaly, though the possibility of a lesser degree of hepatic involvement cannot be excluded. In one patient the appearance of melanogenuria and the development of hepatomegaly occurred during the investigation. Hepatomegaly was not found in any of the patients without melanogenuria (Table I), though several of them showed evidence of extensive metastases elsewhere. All the patients with melanogenuria died within the period of the survey or shortly afterwards. Thus the onset of melanogenuria is associated with a poor prognosis, whether or not hepatomegaly can be demonstrated.

Rothman (1941-2) has suggested that there may be a renal threshold for melanogens, which might explain the low incidence of melanogenuria among patients with malignant melanomi.. Plasma and urinary melanogen levels were found to be $10 \mu \mathrm{g}$./ $\mathrm{ml}$. and $1.4 \mathrm{mg} . / \mathrm{ml}$, respectively, in a patient with gross melanogenuria-showing a concentration ratio similar to that reported by Duchon and Pechan (1963). The melanogen clearance was calculated to be $100 \mathrm{ml} . / \mathrm{min}$. ; it was not possible to conduct any formal tests of renal function on this patient, but a clearance of this magnitude makes it unlikely that there is any renal barrier to the excretion of melanogens.

Decreases in melanogen excretion following administration of cytotoxic drugs to the patient (Case 6), as shown in Fig. 2, were in accord with obvious clinical improvements, though it is not possible to deduce from these results which drug was the more effective. Similarly, there was a reduction in the melanogen output when another patient was treated with cytotoxic drugs. We believe that investigations of melanogen excretion may provide objective evidence of the effectiveness of cytotoxic crug therapy in malignant melanoma.

\section{Summary}

Spectrophotometric and paper chromatographic studies were made of the melanogen excretion of all patients entering the hospital who had at any time had a confirmed diagnosis of malignant melanoma. In 14 months 32 patients were investigated.

Indole melanogens were found in seven of these patients, five of whom had hepatomegaly. The possibility of hepatic involvement in the other two cannot be excluded.

The onset of melanogenuria is associated with a poor prognosis whether or not hepatomegaly is present.

The melanogen clearance was estimated to be $100 \mathrm{ml} / \mathrm{min}$. in one patient. A renal barrier to melanogen excretion seems unlikely.

Melanogen excretion was reduced by the administration of cytotoxic drugs in parallel with clinical improvement.

We would like to thank Professor G. W. Taylor, Mr. C. Naunton Morgan, Mr. H. B. Stallard, and the medical and nursing staff of their wards for their co-operation in this investigation. We are grateful to Dr. C. W. Havard for his help in the studies on the patient from the North Middlesex Hospital, and to Mrs. S. Brown for her skilled technical assistance.

\section{REFERENCES}

Beeler, M. F., and Henry, J. B. (1961). F. Amer. med. Ass., 176, 52 Blackberg, S. N., and Wanger, J. O. (1933). Ibid., 100, 334. Duchoň, J., and Gregora, V. (1962). Clin. chim. Acta, 7, 443. auchon, Pechan, Z. (1963). Ann. N.Y. Acad. Sci., 100, 1048. $\overline{\text { Eppinger, H. (1910). Biochem. Z., 28, } 181 .}$

Jepson, J. B. (1960). In Chromatographic and Electrophoretic Tech-

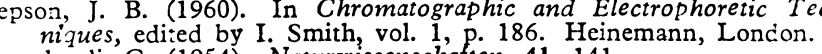
Leonhardi, G. (1954). Naturwissenschaften, 41, 141.

Pechan, Z. (1959). Neoplasma, 6, 397.

Rothman, S. (1941-2). f. Lab. clin. Med., 27, 687.

scott, J. A. (1962). Lancet, 2, 861.

Ttormählen, J. (1887). Virchows Arch. path. Anat., 108, 317. 